Check for updates

Kent

Cite this as: BMJ 2021;374:n2261 http://dx.doi.org/10.1136/bmj.n2261 Published: 14 September 2021

\title{
Covid-19: Booster doses to be offered to 30 million people in UK
}

\section{Jacqui Wise}

Booster doses of a covid-19 vaccine are to be offered to the highest risk groups in the UK as a result of new advice from the Joint Committee on Vaccination and Immunisation.

A booster dose will be offered to all people who were vaccinated during phase 1 of the vaccine programme, no earlier than six months after they received their second dose. The JCVI advises a preference for the Pfizer-BioNTech vaccine regardless of which vaccine someone had for their primary doses. This follows data from the Cov-boost trial that indicated that this vaccine is well tolerated as a third dose and provides a strong booster response.

The JCVI said that it was taking a "precautionary position" and that on balance it was preferable to maintain a high level of protection in vulnerable adults throughout winter. Early data concerning older people from Public Health England indicated that the protection provided by vaccines against severe covid-19 illness decreased gradually over time. However, there wasn't enough time to know what levels of protection might be expected six to 12 months after the primary course of vaccine, it said.

Speaking at a Downing Street briefing, England's deputy chief medical officer Jonathan Van Tam said this winter could be "bumpy at times" and that other respiratory viruses were highly likely to make their return. "The mantra is to stay on top of things," he said.

Health secretary Sajid Javid told parliament that the government had accepted the JCVI's advice and the NHS expects to begin the booster programme next week. "This booster programme will protect the most vulnerable through the winter months and strengthen our wall of defence even further," he said.

The new recommendation means that about 30 million people will be offered a booster dose this winter, including people living in care homes, everyone over the age of 50, frontline health and social care workers, and people with underlying health conditions that put them at risk of serious illness.

The JCVI advised that the booster dose should be offered to the priority groups 1 to 9 in the same order as in the initial rollout. People vaccinated early during phase 1 will have received their second dose around six months ago so it would be appropriate for the booster programme to begin within days, as soon as operationally practical.

Earlier this month the JCVI advised that people with severely weakened immune systems should have a third vaccine dose as part of their primary covid vaccination schedule. ${ }^{1}$

Half a dose of the Moderna vaccine has also been authorised for use as a booster and may be offered as an alternative to the Pfizer-BioNTech vaccine. Where mRNA vaccines cannot be offered, for example because of allergies, the AstraZeneca vaccine may be considered for people who received it previously, the JCVI advised.

June Raine, chief executive of the Medicines and Healthcare Products Regulatory Agency, told the Downing Street briefing that the data showed that giving a covid booster at the same time as flu vaccines was safe and would not affect an individual's immune response to either vaccine. Van Tam said that there may be practical operational considerations that make this not possible, such as because of the need for patients to stay for 15 minutes after they've received an mRNA vaccine. He added that it was "not beyond the realms of scientific possibility" that a combined jab for covid-10 and flu will be possible some time in the future.

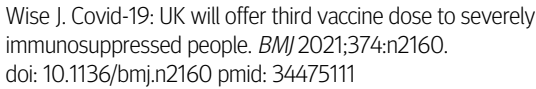

This article is made freely available for use in accordance with BMJ's website terms and conditions for the duration of the covid-19 pandemic or until otherwise determined by BMJ. You may use, download and print the article for any lawful, non-commercial purpose (including text and data mining) provided that all copyright notices and trade marks are retained. 